\title{
Aspectos psicosociales de la corrupción, la violencia y el ejercicio del poder en el Perú
}

\author{
Psychosocial aspects of corruption, violence and the exercise of the power \\ in Perú
}

Víctor Montero López ${ }^{1}$

Universidad Nacional Mayor de San Marcos

Recibido: $18-05-17$

Aceptado: $01-06-17$

\section{Resumen}

El Poder se desenvuelve en muchos espacios, el artículo muestra la motivación de poder, el poder en la historia, la relación poder y violencia, el poder y los grupos, el poder y la identidad, el discurso y la adicción al poder, la relación poder y sexo, el poder del dominado. Y se concluye con un ejemplo de cómo se construye personajes corruptos similares a Montesinos ex asesor de Alberto Fujimori, en lo que se denomina "el pequeño Montesinos".

Palabras clave: Adicción al poder, psicohistoria, identidad, sexo, dominación.

\begin{abstract}
Power is developed in various areas, the article shows the motivation of power, power in history, the relationship power and violence, power and groups, power and identity, discourse and addiction to power, the relationship power and sex , power dominated. And it concludes with an example of how similar corrupt characters is built Montesinos former adviser to Alberto Fujimori, in what is called "the little Montesinos".
\end{abstract}

Keywords: Addiction to power, psychohistory, identity, sex, domination.

1. Universidad Nacional Mayor de San Marcos. Email: vmonterol@unmsm.edu.pe 
La Psicología nos brinda diversos estudios, investigaciones y experimentos sobre los temas abordados. Es así se ha revisado y analizado las producciones de Hoffman, Milgram, Bejarano, Berne, Dyer, Feierabend, Gurr, Geen, Baron, Rabbie, Fiske y Taylor, Ash, Heider, Sherif, Lewin, Morales, Apfelbaum, Sachdev, Bourhis, Wallon, Oberschaall, Turner, Killian, Zurcher, Snow, Blumer Mauss, Tilly, Miller, Javaloy,Tajfel, Klandermans, Rotter, Sabucedo, Skinner, Piaget, Sánchez Rodríguez, Fource, Nevado, Sartre. Y en nuestro país a Franco, Mariátegui, Silva, Delgado, Montoya, Miro Quesada, Vargas Llosa, Barba, Sánchez L.A., Basadre, Gonzales Prada, Arroyo. Además, el autor ha realizado diversos estudios e investigaciones sobre el tema.

\section{MÉTODO}

Se realizaron diversos estudios en base a encuestas, entrevistas, focus group, observaciones participantes, análisis de contenido en los medios e investigación documental y bibliográfica, en base al análisis se llega a conclusiones. Se analizaron a los autores mencionados en la introducción.

\section{RESULTADOS}

Los espacios donde se desenvuelve el poder son muchos entre ellos el familiar, laboral, escolar, social. Empero, en la vida cotidiana estos espacios se integran y en todos ellos el ejercicio del poder se relaciona. Muchas veces este poder se torna en adicción. A través de diversas metodologías se logra comprender la dinámica de estos fenómenos. La importancia es grande en tanto se puede visualizar cómo el poder es un eje transversal que recorre nuestra cotidianidad (Montero, 2005, 2016).

Igualmente, es substancial porque como veremos se relaciona con la identidad, sexualidad y también con las relaciones de dominación y obediencia que responden a necesidades de conformidad, adaptación e influencia social.

La socialización familiar tiene uno de sus ejes en la disciplina (Hoffman, 1981), que se presenta bajo 3 formas: afirmación de poder, retirada de amor, e inducción. Nos centraremos en la afirmación de poder que usa 3 formas: uso de la fuerza física, retirada de privilegios, o amenaza. Ello es sugestivo porque ocurre algo similar con un gobernante, que presentar una actitud similar a un padre que utiliza alguna de estas 3 formas. En ambos casos puede surgir el autoritarismo.

Pero, la influencia social se da sea por la conformidad o la obediencia. Existe una presión a conformarse para disfrutar de aceptación y compartir status y el deseo de estar de acuerdo con la posición del grupo; a su vez, la presión de obedecer es ejercida por una autoridad con elevado status. Es así que esto se conforma desde los primeros años con los padres.

Milgram (1980) concluye de sus experimentaciones que un grupo esencial de personas hacen lo que se les manda, sin interesar el contenido del acto 
ni las limitaciones de su conciencia, en tanto la orden venga de una autoridad genuina”. Las contextos que intervienen en la obediencia son: La proximidad de la víctima; la proximidad de la autoridad; la dispersión de la responsabilidad; que un modelo desobediente se presente. En el caso de la familia se dan a favor de la obediencia la proximidad de la autoridad y podría presentarse un modelo desobediente, pero en contra se da por lo general la proximidad de la víctima y es difícil se dé la dispersión de la responsabilidad. De allí, la importancia de una familia democrática donde se da una autoridad auténtica, dialogante y crítica, y lo peligroso de otro tipo de tipos de familias que se dan en alta proporción como la permisiva, autoritaria y negligente (Montero, 2016)

Pero algunas condiciones son muy frecuentes en la sociedad en términos de favorecer obediencias ciegas, pues muchas veces la víctima no está próxima, y se diluye la responsabilidad, ambas por falta de políticas adecuadas; pero muchas veces la autoridad no está próxima y surgen desobedientes, lo cual cuestiona la autoridad. En ambos casos, el que la autoridad democrática no se asocie a condiciones favorables a una obediencia crítica y la autoridad fascista o dictatorial si se asocia a condiciones favorables a una obediencia, genera ceguera y hasta preferencia por el autoritarismo.

Incluso, esto se da con los intelectuales. Mariátegui (1930) señalaba que muchas veces la Inteligencia se somete a la Fuerza, sobre todo cuando esta es, como la del fascismo, joven, resuelta, intrépida y inquieta, "El idilio entre la inteligencia y el aceite de ricino ha terminado", pero aclara que los intelectuales no cambian su actitud ante una fuerza en ese caso el fascismo. La que cambia son los grupos y poderes dominantes. La inteligencia es substancialmente comodona. El papel de los eruditos en la historia resulta, en verdad, muy sencillo. Ni el arte ni la literatura, a pesar de su delirio de grandeza, gobiernan la política; acatan a ella, como otras actividades más modestas lo hacen. Los intelectuales son los clientes del orden, de la tradición, del poder, de la fuerza, etcétera, y, cuando se requiera, del garrote y del aceite de ricino". Inteligencia y autoritarismo no se oponen necesariamente.

\section{LA MOTIVACIÓN DE PODER}

La motivación de poder es otro elemento clave porque ello define la forma de ejercicio y la relación con los otros. La motivación de poder, es un deseo de las personas por obtener o mantener el control de los medios que les permitan gobernar, someter o influir en el comportamiento de las personas. Puede estar encauzado al provecho personal o al crecimiento institucional.

Según Kendall (2011) "el poder es la capacidad de las personas o grupos para llevar a cabo su voluntad incluso cuando otros se oponen" y agrega que la institución social por la cual se adquiere poderes la política. 
La motivación de poder puede ser benéfica y tornarse en generosidad y el altruismo, pero se convierte en antisocial si se orienta en forma de violencia incontrolada y destructiva.

Pero el poder condiciona toda una lógica en la sociedad que envuelve al que la asume, y así se puede convertir en víctima o victimario. De tal manera que en el ejercicio del poder surge una apetencia por tener cada vez más control, dando lugar a una adicción en aquel que lo ejerce. Y cuando se pierde el poder ello puede hasta provocar desatinos, similar a la adicción, que al dejar la droga provoca graves trastornos de personalidad y orgánicos que hasta lleven al suicidio. Es así con tal de no perder el poder las personas manipulan, se vuelven autoritarias, emplean la tortura, caen en la corrupción, etc. Encima el dogmatismo lo justifica con la frase "el fin justifica los medios".

\section{EL PODER EN LA HISTORIA}

La historia nos muestra abundantes casos de emperadores y gobernantes que han ejecutado los actos más insensatos; pero a su vez, ni gozaban el poder porque la paranoia los abrumaba o la crueldad los motivaba; pero era lo único por lo que eran víctimas de su poder, incluso lo espacial se convertía en prisión pues no podían salir de sus palacios (como en emperadores de España, India, China, etc.).Muchas veces, estos tiranos al pretender tener un poder ilimitado, tomaban decisiones muy necias transgrediendo la libertad (Bejarano, 2008).

El tirano se percibe como necesario, es mesiánico, se cree indispensable. Cree que se mantiene en el poder porque es imprescindible y demandan que él continué. Adopta poses de salvador que combina con el de perseguidor y posibilita el continuismo, pero el triángulo tarde o temprano se agota, y como en todo juego psicológico manipulador en algún momento él se convertirá en víctima (Berne, 1981; Dyer, 2000).

La historia revela luchas por el poder entre padres e hijos, esposos, hermanos, amigos, etc. Son testigos los muros de la Santa Inquisición donde hay escritas frases como esta: "Dios mío protégeme del amigo en que confío, que del que desconfío me cuido yo".

\section{EL PODER Y LA VIOLENCIA}

Estudios diversos mencionan relación entre frustración-agresión y violencia política (Feierabend \& Feierabend, 1969). La frustración sistémica se asocia a la desigualdad entre el nivel de alfabetización y de modernización y el grado de desarrollo. Silos valores son similares, no discrepan y no hay frustración. Así, países políticamente más estables son más equilibrados. Otros señalan que coerción y represión política también producen estabilidad política. 
Otra asociación es entre violencia política y grado de privación, relacionado a grados de bienestar (Gurr, 2015). Se crean así expectativas que detallan mínimos aceptables (Clemente, 1989, 1992) .

Empero, se ha objetado anteriores explicaciones de la violencia, indicando que el potencial de la violencia política real depende del control coercitivo del poder dominante y el contrapoder de la oposición (Geen, 1990, cit. Baron \& Byrne 1998). Es clave el concepto de frustración, las condiciones estructurales de la violencia, características grupales, relacionales e interactivas y los condicionantes psicológicos. Sería más preciso relacionarla a la variedad de situaciones y procesos implicados. Otro aspecto es la activación emocional. Concluyéndose que era más difícil para los grupos que para los individuos suprimir la expresión colérica y sustituirla por un análisis racional. Aspectos afectivos hacen a los grupos más vulnerables al peligro de ceder ante esta violencia (Rabbie, 1989). Los grupos muestran mayor necesidad de autoafirmación y mayor inclinación a usar el poder represivo.

Muchas veces, se asocia la riqueza al poder, y a veces la ambición, falsas emociones (como triunfo maligno, resentimiento, envidia, etc.), los antivalores, la irresponsabilidad, trastornan hasta las relaciones más cercanas. Es así que a veces, en una familia el padre es hijo, el hijo es el padre, la hija es la pareja. O entre amigos y hermanos: tu enemigo es tu amigo, tu amigo es tu enemigo, tu amigo es tu hermano, tu hermano es tu enemigo (Montero, 2016), lo cual es muestra de la violencia social, familiar y sexual.

\section{EL PODER Y LOS GRUPOS}

Otros estudios muestran como las personas según su sociedad tienen esquemas limitados sobre las relaciones de poder, responden a un mapa cognitivo y tienen un tratamiento y procesamiento de la información típico (Fiske \& Taylor, 1991). Por ejemplo, en Occidente procesan más la información dada por las personas que tienen poder.

El poder se relaciona con los grupos. Los grupos dependen mucho de la interdependencia de los miembros (Ash, 1974; Heider, 1958;; Lewin, 1952). Los grupos eran más o menos cohesivos, tenían más o menos poder sobre sus miembros y, según dicho poder, ejercían más o menos presión sobre sus miembros para que se ajusten en normas y decisiones grupales. Así era más sencillo cambiar a todo el grupo que la conducta de un sujeto.

Existe un efecto combinado de poder, tamaño y status. Se ve así que el tamaño y el status de estos afecta la percepción. A su vez, el poder se refleja en las opciones conductuales disponibles, independientemente de la identificación. Pero el tipo de relación de los grupos afecta las estrategias de justicia (Morales, 1998; Apfelbaum, 1979; Sachdev y Bourhis, 1991; Bronfenbrenner, 1987; Wiesenfeld, y 
Sánchez, 1995). Es así como es que según el grado de poder, surgirá el favoritismo, discriminación, el afán de perpetuación, el empleo de la fuerza. Es por ello, muy común que el grupo que constituye el entorno del gobernante lo presione por ejercer el poder para que trate de tener mayor control y busque perpetuarse, esto para mantener sus privilegios.

Los estudios señalan así que los dominantes discriminan más que los sin poder, y que aunque las minorías usaban menos estrategias de justicia, las mayorías usaban con más frecuencia estrategias diferenciadoras (Sachdev y Bourhis, 1991). A su vez, los grupos dominantes (sean mayoritarios o minoritarios) discriminaban.

Otro tema es, la búsqueda de lugar en el grupo vs. la búsqueda de poder en el grupo. El grupo demanda se avance en niveles de liderazgo, para tener lugar permanente en el grupo hay que avanzar en liderazgo, pero esto da lugar a la búsqueda de poder, lo cual va a llevar a competir con el líder, si no se soluciona esto y ello se da en un grupo caudillista, el grupo se fraccionará (Wallon, 1980).

El poder se vincula a los movimientos sociales, estos pasan por varias etapas: emergencia, integración, burocratización y fragmentación y cese (Oberschaall, 1973; Turner \& Killian, 1972; Zurcher \& Snow, 1981; Blumer 1969, Mauss, 1975; Tilly, 1978). La fragmentación y cese del grupo (Miller 1983) ocurre por 4 causas: 1) si logra sus objetivos, 2) si acaba el interés en sus objetivos o agota sus recursos (burocratización o rutina que genera conflictos internos), 3) represión de sufra, dificultad de ganar miembros, sostenimiento de liderazgo o actividades que lo justifiquen; 4) líderes que son seducidos por el poder social (por dinero, prestigio o recompensas).

El poder se relaciona con el control social, así en el ejercicio del poder aparecen estereotipos y se presta una atención diferenciada. El poder y el estereotipar se refuerzan mutuamente, y esta interacción se ve mediada por la atención. Aquellos con menos poder prestan atención las que lo tienen, mientras que las que ejercen poder prestan menos atención y tienden a estereotipar sea porque lo necesitan para obtener los resultados deseados, tienen sobrecarga atencional o no desean prestar atención por su necesidad de dominancia (Morales, 1998; Javaloy, Cornejo y Bechini, 1990).La propagación de estereotipos sirve a la justificación de acciones cometidas o planeadas contra los exogrupos (Tajfel, 1984).

\section{EL PODER Y LA IDENTIDAD}

Poder e identidad van de la mano, lo cual significa tener un tipo de relación grupal (Tajfel, 1984). Y se vincula con la distinta estructura de las relaciones intergrupales (sobre la base de diferencias de status, poder o carácter minoritario y mayoritario o sobre la base de la estabilidad o permeabilidad de la estructura) y sus consecuencias. 
Poder y autoestima también se articulan por los procesos de comparación social. Esto demanda analizar cómo los individuos contribuyen a las funciones de justificación y diferenciación grupal. También se relacionan por el hecho de que la autoestima condiciona comportamientos y es una habilidad clave para manejar conflictos y tomar decisiones (Montero, 1998).

El Poder también se relaciona con el locus de control (interno o externo); en caso sea externo asocia la idea del destino o el azar; en caso del interno lleva a una mayor participación, aunque a veces no se asocia participación política y locus de control. Aquí, es importante distinguir entre participación política convencional y no convencional, y entre acciones instrumentales y expresivas (Klandermans, 1984).

Rotter $(1964,1975)$ maneja el término powerlessness, percepción de parte del sujeto de que su conducta propia no puede determinar los resultados deseados. Klandermans, precisa que sujetos con orientación interna participan más por considerar las actividades políticas como eficaces. Mientras, los sujetos externos que atribuyen al sistema la falta de control, buscan reducir sentimientos de powerlessness.

La participación se relaciona con el grado de desconfianza, esta se concreta en actitudes negativas hacia los dirigentes políticos y la forma de gobierno. A su vez, la motivación por el mundo político dependería si se trata de sujetos activos políticamente o que no lo son (Sabucedo, 1988).

La búsqueda de poder y el estilo de gobernar se relacionan con la personalidad. El tipo de personalidad da lugar a diferentes estilos de ejercer el poder: autoritario, democrático, y el dejar hacer-dejar pasar. Igualmente, el optar por uno u otro estilo depende del tipo de personalidad (Franco, 1980).

Los fenómenos descritos se dan en nuestra realidad combinados con el estilo de comunicación y comportamiento llamado "lenguaje criollo" (Silva, 1978), el cual a su vez vincula con el arribismo (Delgado, 1972). Es sí que asociados a este afán por arribar (o "trepar") aparecerán la sobonería, el acomodo, el burlarse o el relajamiento de moral o principios (expresado en términos asociados a estafar o mentir) que son aceptados y hasta valorados como "viveza". Es una antimoral que afirma que "todo vale", se inserta así un conjunto de antivalores en la cultura de poder en el Perú (Montoya 2002). Contrario a ello, la historia muestra que es posible la afirmación de principios y de una ética en la política (Miro Quesada, 2000, 2016, Vargas Llosa 2012). De allí, la importancia de estudiar fenómenos como la libertad, dignidad y castigo (Skinner, 1978) y el desarrollo moral (Piaget, 1972).

A veces, conviven como en el Perú dos personalidades como señala Yamamoto, el peruano respetuoso: empático, respetuoso de los derechos de los demás y culto en su manera de comunicarse y relacionarse; y el peruano desubicado: egoísta, 
envidioso y chismoso, busca su propio provecho incluso a costa de los demás, es infeliz ante los logros del otro y los descalifica si ve la oportunidad.

El experimento del profesor Ron Jones, sobre la obediencia, muestra cómo es muy fácil que las personas puedan adoptar conductas fascistas aún en las sociedades libres, esto combinando criterios de obediencia, disciplina, sentido de pertenencia, orgullo, el paso a la acción, el liderazgo. Mostró que con varias operaciones, es posible estimular a una multitud de personas a portarse sin pensar siguiendo a un líder, a que rija en estas personas un único pensamiento sin cuestionarse sus actos, porque son deseos de su líder. Se consideran parte de esa comunidad. Es su estilo de vida (Sánchez 2012, Rodríguez 2011).

\section{EL DISCURSO Y LA ADICCIÓN DEL PODER}

Existe un discurso del poder, y a partir de este se busca controlar a la población, surge allí el afán de manipulación cuando se intenta a toda costa mantener el control. De allí prima el afán de controlar los medios de comunicación y de desarrollar técnicas de manipulación que incluyen la guerra psicológica. El poder no puede obviar pues el discurso, ambos van unidos, el reto es que este sea democrático (Montero, 2017).

Pero hay sujetos privilegiados de poder, además de los políticos, existen otros personajes con tanto o más poder que ellos, estos son sobre todo las estrellas (sean del cine o TV, o deportistas), la Iglesia y los "comunicadores estrellas" (Montero, 2017).

El afán de poder cuando se convierte en adicción, muchas veces da lugar a la aparición de un entorno cercano donde reina la mediocridad, pues se prefiere el halago y subordinación a la capacidad (Barba, 1993). Pero la adicción al poder tiene todas las mismas características de otras adicciones, como no tener control sobre sus comportamientos y no poder detenerse una vez que se empieza, hay una fijación en el pensamiento, etc.

Querer ser importante y dominar, sea en nuestra vida o en la de los demás, es un sentimiento que la mayoría sentimos alguna vez en nuestra vida. Lamentablemente, para algunos el poder se transforma en adicción. De acuerdo a un estudio publicado por la revista Journal of Experimental Social Psychology, personas con bajo estatus que llegan a puestos de mucho poder tiende a degradar a los demás, sintiendo placer. Así el poder puede ser adictivo. Un adicto al poder es alguien que necesita demostrar que tiene dominio sobre los demás en todo momento. Esto se identifica cuando: 1. Dan mensajes que lastiman o denigran, 2. Interrumpen, 3. No asumen sus errores porque siempre tienen la razón, 4 . Se jactan de sus acciones.

Dentro de las motivaciones sociales básicas está el poder. Y se puede tener adicción al poder (Fource, 2015, Portalatín, 2015). Se trata de una necesidad permanente de estar en lo más alto, de tener relevancia. Es una de las adicciones 
sin drogas. Una adicción que en algunos casos puede asemejarse a las personas seducidas por el juego o sexo. Al igual que en éstas, la motivación no es tanto la recompensa sino el mantenimiento y el proceso. El poder llama al poder y cuando consigues algo, quieres más.

El hecho de creerse omnipotente y omnipresente genera adicción. Hay dos rasgos de personalidad muy típicos que se asocian con esta ambición: la narcisista y la paranoide, entendida esta última como o estás conmigo o contra mí. Piensan que el mundo gira alrededor suyo y que pueden hacer lo que quieran sin rendir cuentas a nadie, ni siquiera a los de su propio grupo. Su personalidad es típicamente totalitaria (Portalatin, 2015).

Pero el poderoso tiene que tener un equipo de técnicos para gobernar y actuar con eficiencia. Por eso, el poder se relaciona también con la inteligencia, que mantiene una relación peculiar con él. Existe toda una serie de relaciones muy interesantes entre el intelectual y el técnico con el político. El intelectual o el técnico influye en el político, pero otro es su interés y su forma de actuar, este requiere de cierta autonomía y le preocupa el cumplimiento de misiones, objetivos, planes, metodologías, procesos, etc. mientras que repetidas veces el político o gobernante quiere subordinar todo a la imagen. Los intelectuales o técnicos pueden orientar para que se siga determinados caminos o se asuma determinadas concepciones y hasta opciones con su asesoría, pero a su vez tiene como problema el correr el riesgo de ser usado y hasta arrojado cuando ya no lo necesitan o cuando su actitud científica entraba o contradice la actitud de "el fin justifica los medios". Paradójicamente en países como el nuestro donde la democracia tiene limitaciones, por la actitud poco democrática de los partidos que sólo trabajan con sus más allegados, que a veces ni los elige el partido sino el jefe del mismo, es que en algunos gobiernos donde no hay un partido detrás, por la necesidad misma de contar con técnicos especializados, es que se posibilita captar un significativo número de técnicos calificados que encuentran más posibilidades de actuación que en contextos democráticos donde teóricamente esto se debería posibilitar más.

Pero a su vez, el intelectual puede actuar muy contrariamente a criterios científicos o artísticos, que tienen un lenguaje diferenciado, que es abstractosimbólico o mediador entre lo abstracto-simbólico y lo sensible, e implica otro tipo de poder y formas de influir sobre la sociedad. Cuando esto sucede, hemos visto a muchos intelectuales justificando a los peores dictadores, apoyándolos o nutriéndolos para que puedan manipular o reprimir mejor. Es así el caso increíble de Dalí, Chocano, Toscanini, Cela, etc. que justificaban las atrocidades del poder, apoyaban, o admiraban a dictadores. A tal punto que, a veces eran más crueles que estos, es el caso de que aconsejó a Estrada una masacre descomunal, pero como la propuesta era tan sangrienta el mismo dictador se aterró y no se animó a realizarla (Bejarano, 2008). Y siempre encontramos intelectuales que al dar su apoyo hasta sacrifican su rol histórico actuando de forma paradójica en momentos 
extraordinarios o situaciones cumbres (como diría Sartre). Es el caso de Macera que es un valor de la nación, maestro, sabio, continuidad histórica y hasta fue tomado como oráculo, todo ello hoy cuestionado por su apoyo a Fujimori, más aún cuando ha tenido una opinión diferenciadamente de él sobre el MRTA, Sendero, el Estado; y hasta en unas Elecciones anteriores prestó su imagen pronunciándose sobre Barrantes como continuidad histórica. Es evidente que él puede valorar a Fujimori, indicar su valor histórico y personal, pero otra cosa es ser usado para justificar una continuidad que contradice todos los valores y principios que él mismo ha defendido; sin embargo, se satanizó a Macera sin entender las causas de su actuación ni analizar sus comportamientos posteriores.

\section{PODER Y SEXO}

Poder y Sexo, es una relación muy sugestiva, un tema a profundizar. Ello nos hace reflexionar sobre la relación de pareja en los gobernantes, el tema mujer y poder, las actitudes sexuales del gobernante, la privacidad y lo público -sobre todo relacionado a la vida de los políticos y las estrellas-, la industria del sexo y su relación con el poder, etc. Es interesante el poder y la fuerza especial que tiene la mujer latinoamericana y especialmente peruana, comparado con otras mujeres, en términos de supervivencia, creatividad y liderazgo y actuación histórica (Sánchez L.A., 1958; Mariátegui 1930, Basadre, 1970). Pero además, otros intelectuales han indicado que frente a la marginación de la mujer del poder, esta ha mandado desde sus espacios hogareños sobre el gobernante (Gonzales Prada, 1989), esto ha hecho interrogarse a muchos intelectuales respecto a quién realmente gobierna. Pero además tenemos todo lo que implica el tema del espionaje donde muchas veces una mujer es el personaje central.

En el Perú esto ha tenido concreción en la creación de organizaciones sociales de base, en el liderazgo de mujeres en la independencia y otros procesos de nuestra historia, en el caso de Leonor La Rosa y otras agentes de inteligencia. En el tema de Susana Higuchi que mostró el machismo peruano al justificarse un conjunto de actos de Fujimori y generó polémicas respecto al comportamiento que debe adoptar la esposa del Presidente, que ya había tenido antecedentes en casos anteriores como el de Clorinda Málaga de Prado, Violeta Correa, la Sra. Delgado de Odría, la esposa de Villanueva, y Pilar Nores, o en Argentina con el caso de la esposa de Menen, que fueron todos ellos temas de debate. También tenemos un poder simbolizado en Karp esposa de Toledo o en Nadine esposa de Humala. Por todo ello, el poder de la mujer es muy peculiar en nuestra sociedad. Evidentemente que la moral no necesariamente es mejor en mujeres que hombres, sino más depende de las personas y no del sexo.

\section{EL PODER DEL DOMINADO}

Otro aspecto es el poder del dominado o de los que son gobernados. Se piensa que el pueblo puede ser manipulado fácilmente, pero este tiene mucho poder 
aunque sea sólo por el hecho de que finalmente es él el que elige a un gobernante. La actuación del Estado peruano que ha marginado por siglos al pueblo y el juego de intereses, ha dado lugar al fenómeno de la plebe urbana (Franco, 1991). Ello genera que el pueblo peruano haya puesto en juego su intuición para el logro de sus objetivos (Montero, 1990, 1994, 1998, 2005) y que a la vez como un arquetipo esté presente el mito de Inkarrí, que toma diversas versiones según las épocas y clases sociales, pero en todas está presente como símbolo de grandeza de un pasado y como símbolo de esperanza en el futuro. Esto último tiene más fuerza que la desesperanza aprendida. Esto ocurrió con Barrantes, Alan, Fujimori y con Toledo. Y actúa como una alternativa a la comunicación oficial dando lugar a rumores o un correr la voz frente a la exclusión de los medios, con la psicología del voto perdido, con la actitud de apoyar al opositor y al más débil. Y en la historia los jóvenes han sido reserva moral que rechaza la corrupción, como señaló Arroyo (2000) para buscar caiga el régimen de Fujimori utilizaron espacios incontrolables como los centros comerciales, las cabinas y los hoteles. Aferrarse al poder irá en contra del que toma esta actitud, como siempre se ha cumplido en la historia.

\section{LA CORRUPCIÓN EN EL PERÚ Y SU RELACIÓN CON EL PODER}

Los estudios de los autores peruanos mencionados señalan aspectos que los medios no dicen: Que el problema de la corrupción es endémico, existen raíces históricas y comportamientos difíciles de erradicar. No es la presencia de corruptos o mafia sino una serie de fallas del sistema de gobierno. Problemas por incentivos y castigos equivocados e instituciones incapaces.

La falta de cumplimiento de ley es un mal terrible. La lucha contra ella implica gran nivel de cooperación de actores. Sin embargo, hay casos como Uganda, que muestran es posible revertirla.

Se habla de ciclos de tiempo de abuso de 10 años. Hay relación entre reformas económicas y corrupción, pero no hay que confundir mercantilismo o liberalismo con corrupción. Los tipos de corrupción son diversos: soborno, peculado extorsión, fraude, tráfico de influencias; la cleptocracia, clientelismo, nepotismo. Un problema grave es que en Perú hay alta tolerancia a corrupción. Corrupción es igual a Monopolio más Discrecionalidad e inverso a Transparencia o rendición de cuentas. Lamentablemente el portal del Estado es no amigable. La teoría neoinstitucional aborda de manera más integral el tema. No se trata de imponer estándares que no se cumplen sino de generar mayor bienestar (Costa y López, 1986).

El perfil del corrupto incluye según los estudios (Hernández, 2015; Peña, 2015): avidez por el poder, licencia para quebrar leyes, maldades no descalifican, se elogia. Lamentablemente a veces la familia solo enseña éxito, poder y dinero. Se produce entonces un arribismo, uso perverso, sádico, racionaliza. Por ello, hay que evitar la concentración de poder y de control; el poder influencia pero depende 
como se ejerce. Hay niveles: personal: psicológica, cultural y política, relación con autoritarismo y el secreto. Implica un encuentro entre deseo y realidad, son complementarios, solo existe en los medios. Muchas veces en la sociedad, no hay amistad, solo privilegio, no empatía sino utilidad, interés y eficiencia; ambición y utilitarismo sin ética. El control ingresa incluso a lo privado. Los medios le dan gran cobertura, teatralidad y lo muestran como imagen de eficiencia y activismo.

Se dice: amistad es admiración, aprecio, afinidad y desinterés. Cuando hay intereses lo que es la admiración se trueca por miedo y recelo de ser superado, el aprecio por desprecio disimulado, la afinidad por complacencia y el desinterés por actitud seudo aséptica (Campos, 2015).

Existe una falla sistémica cuando las otras fuerzas y poderes se rinden por ser de baja calidad. Debe haber un balance de poderes y ser más vigilantes no solo declarativos. No es el Poder Judicial el más destacado en su rol vigilante sino algunos congresistas y algunos medios o periodistas. Es clave la naturaleza del Estado, no Gobiernos débiles y fragmentados sino grado de centralización y capacidad institucional para hacer cumplir las leyes.

Hay que propiciar competencia política. Afirmarun lógica de controles mutuos. Sean Jurados los que decidan y no un juez para evitar corrupción. Reforma de la Constitución para optimizar la salud, educación y seguridad, Reforma electoral para representación proporcional. Empero, frente a escándalos hoy se tolera menos la corrupción. Requerimos lucha anticorrupción y justicia eficiente balanceando el poder, medidas para actuación eficiente de la justicia y evitar impunidad. ONU fortalecer prevención y combate a la corrupción, promover probidad, rendición de cuentas y buena gestión.

En un vídeo o "vladivideo" se ve cómo se reunían empresarios, generales y políticos con Montesinos (es decir el poder económico, militar y político). Frente a ello, se declaró que el BCP aprovechó de la gestión que realizó Dionisio Romero ante Montesinos. Pues como consecuencia de esta gestión, los cuatro profesionales propuestos por Romero fueron nombrados judicialmente como administradores de Hayduk. Esto permitió que estas empresas funcionaran normalmente y que el BCP le pudiera cobrar su acreencia que tenía valor aproximado de 15 millones de dólares. "Montesinos hace lo que tiene que hacer, y sabemos que lo hacía muy bien" dijeron.

Felizmente, los estudios señalan que en Perú la corrupción no tiene redes tan fuertes como en otros países ni como con Montesinos o como estuvo a punto de construir Álvarez, tampoco surge como pacto por gobernar con partidos o con sector privado- nuestros políticos son más antropófagos- pero su dispersión hace su combate mucho más difícil.

Como dice Peña (2015) vivimos un conflicto entre creatividad y destructividad, entre moral e inmoralidad, entre alegría y sufrimiento. Hay rechazo pero también 
identificación. El riesgo es el predominio de individualismo, lo material, el engaño, lo negativo. El cambio es de nosotros, buscar que los valores predominen, no ser tolerantes con la corrupción. La corrupción es una mezcla deseo y temor, miedo y esperanza. Es una repetición compulsiva.

Hernández (2015) señala que el método contra la corrupción va más allá de meter presos a los políticos rivales. Hay necesidad de dialogo y de consensos. $\mathrm{Si}$ digo lo que me da la gana, eso fomenta la violencia, corrupción, el odio. Hay que poner fin a la versión chicha de "la guerra de todos contra todos". El crecimiento económico no mitigó la desigualdad, los instrumentos tecnológicos permitieron que grupos urbanos marginados sintieran incluirse en la modernidad. La sociedad posconflicto se caracteriza por: fragmentación institucional, violencia delincuencial e inseguridad ciudadana. La desconfianza generalizada conspira contra la construcción de lazos solidarios. Se puede sufrir un trastorno de estrés postraumático: el desamparo.

Son tan evidentes las estrategias para eludir la Justicia, que Álvarez Rodrich (2015) hizo un Manual eficaz para control de daño ante una denuncia de corrupción: 1. Plantear su defensa con lógicas distintas: la judicial y la política.2. Negar siempre toda culpabilidad. 3. Atribuir la denuncia a una motivación política. 4. Lanzar su candidatura para reforzar.5. Si aún no se puede lanzar, decir que hay temor por su candidatura.6. Dar su versión en una conferencia de prensa cuando tenga claridad. 7. No pelear con otro acusado. 8. No cambiar de versión a cada rato. Contradecirse solo lo va a hundir. 9. Exigir una investigación a fondo y ofrecer su colaboración. 10. Hablar poco para evitar decir lo que podría lamentar. 11. Todo tiene explicación pero evite decir tonterías o mentiras flagrantes. 12. Decir que no hablará más del caso para no interferir con la justicia. 13. Que su abogado saque la denuncia, del ámbito judicial.14. Promover denuncias a otros políticos. Así desvía la atención, deja la idea de que todos son corruptos.15. Demorar todo lo que pueda para aprovechar la falta de memoria en Perú.

La creciente desconfianza en las instituciones, las irregularidades de la política y el aumento del malestar social, aparentemente serían reflejo de una crisis, que es mundial y muy grave en Perú. Pero tal vez, es un aspecto de nuestra historia, de uso y a veces mal uso de las relaciones humanas para obtener resultados particulares, que viene de la Colonia. Nunca lo habíamos visto como problema, pero ahora se ha visto una trama mucho más grande que afecta la convivencia económica, política y social (Maturana, 2015).

Hoy nos damos cuenta y no nos gusta. No nos gusta lo que está pasando porque tiene que ver con nuestras cegueras de antes. Es una gran oportunidad para salir de esta situación, para cambiar el curso de nuestras relaciones (Maturana, 2015). 


\section{EL PEQUEÑO MONTESINOS}

A veces criticamos a Vladimiro Montesinos (ex asesor del ex Presidente Alberto Fujimori) y hasta se lo sataniza, a veces lo igualamos a un delincuente, a un mafioso, a un narco que aparecen, pero nos olvidamos que si existe es porque hay personas que han permitido se desarrolle, el solo representa magnificado lo que sucede en muchos lugares en Perú, hay muchos pequeños Montesinos. En cada institución puede haber el peligro que surja un pequeño Montesinos, es como un pequeño seductor que poco a poco va seduciendo a todos. Aparece de muchas formas, como un consultor, un asesor, a veces hasta un carga maletas, un adulón, Es una persona que poco a poco va induciendo a los demás, principalmente a los responsables de la institución, la empresa u otro espacio, a entrar en la corrupción, a cometer robos, a engañar, estafar, a cometer nepotismo, a vivir a costa de los otros.

Este personaje justifica toda la corrupción, te dice que se justifica que te apropies de lo que no es tuyo, que la vida es así, que la política es así y qué se le va hacer. Enseña diversas tácticas para despistar al enemigo, para cubrir la corrupción, pero eso si el nunca aparece, el nunca firma. Es soberbio porque cree que a todos puede engañar y manipular (Montero, 2008).

Puede fingir mucha amabilidad y por último que no habla mal de nadie, puede fingir ser afectuoso pero no tiene reales afectos, los intereses lo unen a las personas. Trata de hacerse necesario, simula conoce de muchas cosas, aparenta, es lo que llaman "pantallero". Trata de no chocar con los que no le conviene, parece muy fiel, pero negocia con cualquiera aunque sea opositor.

Este personaje va entrando disimuladamente, trata de hacerse necesario, cuando menos se dan cuenta ya tiene mucho poder.

Se juegan muchos roles ante su presencia, dando lugar a diversas performances de las competencias, sean estas de saber, poder, querer o deber. El finge ser el que puede desempeñar todos estos roles, pero no es imprescindible. Es un ser narcisista que traiciona a cualquiera.

Este personaje es un experto en guerra psicológica o intuitivamente sabe cómo manejarla, por supuesto que emplea la guerra psicológica de tipo de un individuo a un grupo, o puede usar otros tipos de guerra psicológica, pero por lo general, manipula a los demás para que hagan guerra de un individuo contra otro individuo, de un grupo contra otro grupo, de un grupo contra un individuo o de un individuo contra sí mismo. Está siempre listo para enviar dardos al cerebro de los demás para que actúen según sus objetivos o sus deseos.

Igualmente, la estrategia de guerra psicológica incluye utilizado de manera perversa aspectos de lo cognitivo conductual, como manipular los pensamientos automáticos, para desmoralizar o anular. Puede usar perversamente también 
el análisis transaccional promoviendo juegos como promover juegos, la que instrumenta es el que manipula a su favor. El juego sobre todo es el que se llama "peléense los dos", que él o ella mira desde la tribuna y el argumento de vida es el "no vivas" con impulsores como "Trata más para ser Fuerte" o "Se perfecto para Tratar más" o "Apúrate a Complacer". Estudios diversos muestran cómo los jóvenes pueden adoptar estos impulsores (Montero 1998, 2008)

El "pequeño Montesinos" utilizando guerra psicológica puede utilizar el afecto, incluso el sexo para sus fines. Otras veces chantajea o hasta se puede hacer la víctima. Evidentemente es arribista, codicioso, falso, todo se engarza con sus objetivos de control y manipulación.

Cuando algunos se dan cuenta de lo negativo de su presencia, este personaje ya ha echado raíces, para que no sea fácil deshacerse de él o ella. Trata de prolongar su presencia no solo por obtener beneficios económicos, sino es un adicto al poder.

Pero no basta con desconfiar del que tiene fama de inmoral, pervertido, mujeriego, deshonesto, poco honrado, etc. Hay que desconfiar del que aparece disimulado. Hay que prevenir su aparición.

Este pequeño Montesinos cuando habla con el que tiene poder va a hablar mal de todos y va a desprestigiar a todos. Así esta conducta de por sí ya es corrupta.

Finalmente, el pequeño Montesinos se opone al que lo ayudó y los que advirtieron de su presencia alertando a los demás, son ignorados, el grupo ni les reconoce razón. Es como si volvieran a encontrarse con el personaje por primera vez, no ven, no perciben el proceso, lo cual muestra la responsabilidad del grupo pues se cegó, no quiso ver. Vio la presencia de este pequeño Montesinos, como necesario, o como mal necesario, que les es útil y mejor conservarlo. Este pequeño Montesinos obtiene beneficios y luego compromete con sus actos corruptos.

Habrá muchos que han compartido "beneficios" a lo largo de la presencia de este pequeño Montesinos y estarán dispuestos a defenderlo o a darle más poder. Hay pues una complicidad entre el corrupto y otros que lo "conocen" justificándolo.

Por eso, el código moral Inca no solo incluyó el "Ama sua, ama llulla, ama quella" (no robarás, no mentirás y no serás perezoso) sino también el "ama llunk'u", que en quechua significa no seas servil, adulón, zalamero, chupa, sobador, siendo el sentido inicial de llunk'uy, en quechua, es "lamer, relamer con la lengua o los dedos". Esa persona es dañina para el mismo que adula, para el mismo que dice servir. Bien dice el refrán: "El que te adula y lisonjea, su bien y tu mal desea".

Aprendamos a reconocer al pequeño Montesinos que aparece. Tiene antecedentes de robo o malversación, de mentiroso, de perezoso, pero también puede ser un adulón. Incluso a veces se llena de discursos de moralidad y ética, 
criticará los actos de otros como inmorales o cuestionables. Pero si averiguamos mejor su vida o preguntamos a otros tiene antecedentes de corrupción, de conductas psicopáticas y de relajamiento moral. Ahora sabemos que hay delincuentes que desde lejos y hasta desde la cárcel siguen dirigiendo a grupos; o como dice Hildebrandt, las ideas de Montesinos no están presas, sino están en la cabeza de otros; e igualmente sucede con las ideas de Abimael Guzmán. Y recordemos que los espacios privado y público no se excluyen, si en lo privado encontramos motivos para dudar de alguien pues bien porque así actuará en lo público.

\section{PÉRDIDA DE LÍDERES SOCIALES}

35.673 peruanos fueron asesinados o desaparecidos por SL. De estos 12.564 víctimas fueron reportadas ( $54 \%$ del total de víctimas). El 24\% de los asesinados fueron dirigentes sociales. Es decir se reportaron 3,015 y hemos perdido en total 8,561 líderes por terrorismo. Si a esto le sumamos los asesinados por paramilitares la pérdida de líderes nos limita significativamente como país y es difícil reponerse.

A esto se agrega el caso de Odebrecht, que ha creado desconfianza sobre los pocos líderes que tenían arraigo popular, al margen de sus posiciones esto es sumamente grave y ojalá surjan nuevos líderes.

\section{DISCUSIÓN DE RESULTADOS}

Hay que precisar lo específico del poder en los diversos espacios en que se desarrolla. Los congresistas deben reparar en lo grave del desprestigio de esta institución. Es claro que vivimos una crisis de la clase política y se requiere construyan partidos. Es hoy muy claro que la corrupción no es exclusiva de una ideología y que el ejercicio del poder depende mucho de los aspectos protectores de que disponga el que gobierna. A su vez, instituciones como las Iglesias, deben reformarse y darse cuenta de lo grave de acusaciones de abuso sexual, peleas por tener varias parejas, etc., en sacerdotes, pastores y otros. La fe y esperanza es necesaria y muchas veces las personas lo encuentran en la religión.

Hay que profundizar en las formas de construir familia democrática. Al margen del tipo de familia, esta debe brindar apego, y cumplir sus funciones. Es urgente superar estilos de crianza autoritarios, permisivos y desapegados.

Hay que profundizar sobre el tema de la obediencia, como se construyen fenómenos como el fascismo, la permisividad frente a la corrupción y la violencia, los modelos autoritarios, etc.

La motivación de poder incluye muchos aspectos sobre los cuales profundizar, temas como la asunción al poder de Stalin en vez de Trosky, o de Villanueva o Alan en vez de Towsend, son necesarios tratarlos. 
Se requiere seguir trabajando los temas de Psicohistoria para comprender muchos de los hechos acontecidos y sacar lecciones. Basadre daba brillante ejemplo de cómo la Psicología puede aportar a la Historia.

Nuevas formas de violencia han surgido que requieren investigaciones que ayuden a su prevención, como el terrorismo, guerras mundiales, fanatismos.

En los grupos hay que escudriñar más sobre los mecanismos de poder en los grupos, la gestión, emponderamiento y emprendedurismo.

Los estudios de identidad nacional son particularmente importantes al país, Montero (1992) indicó sus componentes, los cuales hay que ahondar.

Los discursos es otro tema relevante, así como los mecanismos por los cuales se produce la adicción al poder.

Igual, hay que detallar la relación poder y sexo, y poder enriquecimiento, que podrían explicar tal vez otros fenómenos como la adicción o corrupción.

El tema de la corrupción es ya un tema clave para la Psicología social, Preventiva y de Salud en el Perú (Montero, 2017).

Hay que seguir detectando aspectos que nos expliquen y con los que podamos prever surja un pequeño Montesinos en las instituciones.

\section{CONCLUSIONES}

- Desde la familia, se forma las nociones de poder, disciplina y autoridad.

- La motivación de poder puede traducirse en generosidad o altruismo, pero si es antisocial se orienta en agresividad y destrucción.

- Un afán por tener cada vez más control, puede convertirse en adicción.

- El tirano por lo general, toma una actitud mesiánica. Como juego manipulador en algún momento él se convertirá en víctima.

- El potencial para la violencia política real se convierta en violencia real depende del control coercitivo del poder imperante y el contrapoder de la oposición.

- Las conductas autoritarias y fascistas aparecen al manipular la obediencia, disciplina, sentido de pertenencia, orgullo, el paso a la acción, el liderazgo.

- Las personas asumen esquemas de su sociedad sobre las relaciones de poder, responden a un mapa cognitivo. 
- El tipo de relación de los grupos afecta las estrategias de justicia. Los estudios señalan así que los dominantes discriminan más que los sin poder, y que aunque las minorías usaban menos estrategias de justicia.

- El grupo demanda se avance en niveles de liderazgo, da lugar a la búsqueda de poder, competir con el líder, si no se soluciona se fraccionará.

- El poder se relaciona con la identidad, lo cual significa un tipo determinado de relación grupal. Esto se articula con la autoestima del individuo.

- La relación con el locus de control da lugar en caso sea externo a la idea del destino o el azar, y en caso del interno a generar mayor participación.

- El afán de búsqueda de poder y estilo de ejercer poder se relaciona con la personalidad. El tipo de personalidad da lugar a diferentes estilos de ejercer poder. Todos estos fenómenos se relacionan con el arribismo y moral.

- Existe un discurso del poder, surge allí la necesidad de manipulación y control. El poder del dominado se relaciona con capacidad de superar desesperanza (Montero, 1992, 2017).

- Somos un país desarticulado, desintegrado y desanimado, prima la cultura de desconfianza y mucha desesperanza.

- Es grave un pueblo populista, conservador, pesimista y sin memoria. Hemos sufrido numerosas frustraciones, necesidad urgente de procesos electorales con principios éticos y morales.

- La corrupción viene desde la Colonia, causa desesperanza, es grave la existencia de la "norma perversa. Urgen cambios de estructuras sobre todo en el Poder Judicial. Todo acto injusto y corrupto ser declarado acto de traición a la patria, porque está afectando al sistema de valores, a la formación de los menores, a la legitimación de la violencia.

- Prevenir desde la pareja y la familia. Es necesario que la familia y escuela, desarrollen valores y estructuras psíquicas que sean barreras y anticuerpos contra la corrupción y la violencia, y logren integrarnos superando la cultura de la desconfianza (Montero, 2016). Necesitamos que todos aprendan a cumplir las reglas del funcionamiento social para construir el bien común y una cultura de paz. Necesitamos aprender todos a respetarnos entre nosotros, aceptando las diferencias, superando los prejuicios, odios, racismo e intolerancia. Los medios pueden ayudar mucho en esta tarea. 
- Hay constante ascenso y descenso vertiginosos de corruptos y violentos, falsa omnipotencia e invulnerabilidad.

- No se trata de encontrar podredumbre en personas que contagiarán a las demás.

- Hay que construir esperanza; el vínculo sano, el dialogo, la comprensión y empatía, estén presentes en todos nuestros espacios vitales.

- Basadre decía que los enemigos del Perú son los podridos, congelados e incendiados; pero que el Perú es más grande que sus problemas.

- La estrategia de guerra psicológica utiliza de manera perversa aspectos de lo cognitivo conductual. Y existe personajes que se convierten en "pequeños Montesinos" creando dependencia en las organizaciones.

- La violencia no es la partera de la historia sino es la historia aquella que es la partera de la violencia. Las guerras solo traen más pobreza, destrucción y sufrimiento a los pueblos y propician conductas perversas.

- Albert Cohen dice en Everybody Knows: "Todos saben que las apuestas están arregladas, y aun así juegan esperando un golpe de suerte. Todo el mundo alardeando de sus riquezas, esperando así cubrir sus carencias con regalos, comprando el amor y reconocimiento social..." Que coincide con Piero al decir en "Ay país": "Las cosas se cuentan solas, solo hay que saber mirar".

- Que el futuro sea nuestro, superando toda fragmentación, desintegración y desánimo; crecer como humanos dignos, y las generaciones venideras reciban un mejor legado.

\section{REFERENCIAS}

Apfelbaum, E. (1979). Relations of domination and movements of liberation, an analysis of power between group, en J.F. Morales, 1989, Lecturas de Psicología Social, Madrid, UNED, pp. 611-670.

Arroyo J. (2000). Juventud, poder y democracia. Lima: Conversatorio Casa Museo Mariátegui.

Asch, S. (1974). Fuerzas de grupo en la modificación y distorsión de juicios. En J.R. Torregrosa y E. Crespo. (Comps.), Estudios básicos de la psicología social. (pp. 351364). Barcelona: Hora

Barba J. (1993). Intervención en Debate Constitucional. Lima: Congreso de la República, tomo 3 https:/goo.gl/eoAAfB

Baron \& Byrne (1998). Psicología Social. Barcelona: Prentice Hall.

Basadre J. (1970). Obras completas. Lima: Pablo Villanueva. 
Bejarano, D. (2008). Revista Desafíos, vol. 18, enero-junio, 2008, pp. 214-241 Colombia: Universidad del Rosario Bogotá.

Berne, E. (1981). Juegos en que participamos. México: Diana.

Blumer, H. (1969). Collective behavior en Lee, Principles of Sociology. Nueva York: Barner \& Noble.

Bronfenbrenner, U. (1987). La ecología del desarrollo humano. Barcelona: Paidós. Clemente, M. (1989). Metodología de investigación de los problemas psicosociales: la investigación sobre evaluación de las intervenciones psicosociales. Revista de Psicología Social, 1, 85-109.

Clemente, M. (1992). Psicología Social Aplicada. Madrid: Eudema.

Costa, M. \& López, E. (1986). Salud Comunitaria. Barcelona: Martínez Roca.

Dyer, W. (2000). Tus zonas erróneas. México: Grijalbo.

Delgado C. (1972). El arribismo en el Perú. Lima: INIDE.

Feierabend, I. K.; Feierabend, R. L. \& Nesvold, B. A. (1969). Social change and political violence: Cross-national patterns. En H. D. Graham \& T. R. Gurr (eds.), Violence in America: Historical and comparative perspectives (pp. 606-668). Nueva York: Signet.

Fiske S., Taylor S. (1991). Cognición social. EEUU: McGraw-Hill

Franco, C. (1980) Personalidad, poder y participación. Lima: Ceder.

Franco, C. (1991) "Imágenes de la Sociedad Peruana: la otra modernidad" Texto Exploraciones en 'otra modernidad': de la migración a la plebe urbana. Lima: CEPEP,

Gonzales Prada, M. (1989). Horas de lucha. Lima: Peisa.

Hernández M. (2015).Esta campaña será crispada y hasta podría ser sangrienta. En Diario Perú 21, 14 julio 2015 https://goo.gl/v9SMXE

Heider, F.(1958). La psicología de las relaciones interpersonales. N. York:Wiley

Hoffman L. (1981). Fundamentos de Terapia Familiar. México: FCE

Javaloy, F., Cornejo, J.M. y Bechini, A. (1990).España vista dese Cataluña: estereotipos étnicos en una comunidad plural. Barcelona: PPU.

Kendall, D. (2011), Sociología de nuestro tiempo. Mexico: Cengage.

Klandermans, B. (1984). Movilization and participation: Social psychological expansions of resource movilization theory. American Sociologcal Review, 49.

Lewin K. (1952). Field theory in social science. Londres: Tavistock.

Mariátegui, J. (1930). Obras completas. Lima: Amauta

Mariátegui, J. (1930). La inteligencia y el aceite de ricino. En La Escena contemporánea. Lima: Amauta.

Maturana, H. (2015). Crisis ética y moral. Santiago: El mostrador. https://goo.gl/fX7NFC 
Mauss, A. (1975). Social problems and social movements. Filadelfia: Lippincott

Milgram, N. (1980). Obediencia a la autoridad, un punto de vista experimental. Bilbao: Desclée de Brouwer.

Miro Quesada, F. (2000). Cuatro versiones de la ética y la moral. https://goo.gl/ZQw1p2

Miro Quesada F. (2016). Ético y eficiente. Lima: Diario El Comercio.

Montero, M. (1991). Acción y Discurso. Caracas: Trillas.

Montero, V. (2017). Metodología de análisis psicosocial de medios de comunicación. Madrid: Editorial Académica Española.

Montero, V. (1992). Psicología e Identidad Nacional, herencia cultural y nacionalismo. Lima: Tetis Graf.

Montero, V. (2017). Psicología de la comunicación social en el siglo XXI. Madrid: Editorial Académica Española.

Montero, V. (2017). Psicología Comunitaria, la experiencia peruana. Madrid: Editorial Académica Española.

Montero, V. (1979). Psicología de masas del aprismo. Lima: UNMSM

Montero, V. (2004). La vida en un video. Lima: Revista Paradigmas Colegio de Psicólogos del Perú, vol. II

Montero V. (2005).Psicología Política y Gobernabilidad en el Perú. Lima: Foro Peruano de Psicología Social.

Montero, V. (1998). Libertad, paz, democracia e identidad nacional. Revista de Psicología Vol. III No 3 Julio 1998. Lima: UNMSM.

Montero, V. (2008). ¿Defectos de intelectuales, pecados comunes o déficits de habilidades? Blog Psicología Política Peruana.

Montero, V. (2016). La pareja en Lima-Perú: estudios en pueblos jóvenes, sectores tugurizados, no tugurizados, sectores medios y jóvenes preuniversitarios. Ponencia a Congreso Sudamericano de Terapia Sexual y de Pareja. Trujillo.

Montero V. (2016). Violencia social y su relación con la violencia sexual en el Perú. Ponencia al Congreso Internacional de Psicología. Lima.

Morales J. F. (1998). Psicología Social. Madrid: McGraw Hill.

Morales J.F. (1984). Hacia un modelo integrado de psicología social aplicada. En J. R. Torregrosa y E. Crespo (Eds). Estudios básicos de psicología social. Barcelona: Hora.

Montoya, R. (2002). Cultura y poder. Lima: Ciberayllu. https://goo.gl/BypziF

Peña S. (2017). Nuestra identidad tiene aspectos creativos, pero también aspectos destructivos. En Diario La República 15 enero 2017. https://goo.gl/h7RcKh

Piaget, J. (1972). El desarrollo moral en el niño. Madrid: Morata. 
Portalatín, B. (2015). La insana adicción al Poder. Declaraciones del presidente de Psicólogos sin Fronteras Guillermo Fourcea Diario "El Mundo" https:/goo. gl/8jvPhf

Rabbie, (1989). Social identity theory: A conceptual and empirical critique from the perspective of a behavioural interaction model (pages 171-202). European Journal of Social Psychology, vol.19

Rotter, J.B. (1964). Psicología clínica. Buenos Aires: UTEHA.

Rotter, J.B. (1975). Some problems and misconceptions related to the construct of internal versus external control of reinforcement. Journal of Consulting and Clinical Psychology, 43, 56-67

Sachdev \& Bourhis (1991).Power and status differentials in minority and majority group relations, European Journal of Social Psychology, 21, pp. 1-24

Sánchez, L.A. (1958). El Perú: retrato de un país adolescente. Buenos Aires, Ed. Continente.

Sánchez, E. (2012).La tercera ola un experimento sobrecogedor. En La mente es maravillosa. https://goo.gl/AZYsyC

Skinner, B.F. (1978).Acerca de los conceptos de libertad, dignidad y castigo. Madrid: Morata

Silva, M. (1978). La ideología del criollo. Lima: Libro viejo.

Turner \& Killian (1972). Collective behavior. Engelwood: Prentice Hall

Vargas Llosa, M. (2012). La civilización del espectáculo. Madrid: Alfaguara

Wallon, H. (1980). Psicología del niño 2 t. Madrid: Pablo del Río*.

Wiesenfeld, E. y Sánchez, E. (1995). Psicología social comunitaria. Contribuciones Latinoamericanas. Caracas: Fondo Editorial Tropykos.

Zurcher \& Snow (1981). Collective behavior. Social movements, en M. Rosenberg y Turner, Social psychology. Nueva York: Basic Books. 